\title{
CONTRIBUTION OF ETHYLENE TO THE CADMIUM RESISTANCE OF THALE CRESS (ARABIDOPSIS THALIANA)
}

\author{
LU, X. Y. ${ }^{1}-$ CHEN, Q. ${ }^{2}-$ CUI, X. Y. ${ }^{*}-$ ZU, Y. G. ${ }^{1}-$ TANG, Z. H. ${ }^{1}$ \\ ${ }^{1}$ Institution Northeast Forestry University, Harbin 150040, China \\ ${ }^{2}$ School of Life Sciences, Nantong University, Nantong 226010, China \\ *Corresponding author \\ e-mail: c_xiaoyang@126.com; phone: +86-451-8219-2198 \\ (Received $7^{\text {th }}$ Jun 2019; accepted $10^{\text {th }}$ Oct 2019)
}

\begin{abstract}
Ethylene was reported to be important in the response to cadmium (Cd). It is generally agreed that ethylene could improve $\mathrm{Cd}$ resistance, but the specific mechanism is not yet clear. To make up for this gap, this paper explores the antioxidant capacity, malondialdehyde (MDA), hydrogen peroxide $\left(\mathrm{H}_{2} \mathrm{O}_{2}\right)$ content, $\mathrm{Cd}$ content and the expression of relevant genes in Arabidopsis thaliana seedlings, and examines the effect of ethylene on the physiological performance of $\mathrm{Cd}$-stressed seedlings. The results show that ethylene could greatly improve the $\mathrm{Cd}$ resistance of plants by suppressing the translocation of $\mathrm{Cd}$ ions. In addition, ethylene can ease the metal phytotoxicity of $\mathrm{Cd}$ by lowering the MDA content and $\mathrm{H}_{2} \mathrm{O}_{2}$ generation, and regulate the over-expression of AtATM3 and APDR8 to enhance Cd resistance. To sum up, ethylenecould enhance $\mathrm{Cd}$ resistance by enhancing antioxidant activity and inhibiting the translocation of Cd ions.
\end{abstract}

Keywords: ethylene, cadmium $(C d)$, resistance, gene expression, translocation factor

\section{Introduction}

Cadmium (Cd) is ubiquitously distributed in the environment, it is non-essential and toxic to the human body. Because of its high-water solubility, the element can easily be absorbed by plants from Cd-contaminated soil, and can interfere in nutrient absorption and translocation, leading to nutrient imbalance (Järup and Akesson, 2009). The uptake of $\mathrm{Cd}$ by plants is accelerated under $\mathrm{Cd}$ stress. A high content of $\mathrm{Cd}$ ions may inhibit plant growth, reduce biomass accumulation and even cause cell death. The $\mathrm{Cd}$ can also affect membrane function by inducing lipid peroxidation. In addition, the element tends to boost the production of oxygen free radicals and suppress that of enzymatic antioxidants, leading to oxidative stress (Gratão et al., 2012; Monteiro et al., 2011).

Many scholars have proved that $\mathrm{Cd}$ stress has the potential to cause the following issues: the accumulation of reactive oxygen species (ROS), the inactivation of antioxidant enzymes, damages protein and DNA and negatively influences lipid peroxidation (Mishra et al., 2006; Ranieri et al., 2005; Schützendübel et al., 2002). Focusing on the Cd-resistance of ethylene, Zhang et al. (2010) investigated the effect of ethylene on the $\mathrm{Cd}$ uptake and accumulation of plants at different $\mathrm{Cd}$ contents, and found that plants with high translocation factor are less tolerable to Wang et al. (2011) observed that $\mathrm{Cd}$ and Cd-containing toxic compounds were excluded from the cytoplasm of Arabidopsis, with the increase in the expression of AtPDR8, indicating that transport gene is contributing to $\mathrm{Cd}$ resistance. The studies of Chen et al. (2018) showed that exogenous application of $\mathrm{Cu}, \mathrm{Zn}$ or $\mathrm{Ca}$ to plant medium could alleviated the Cd stress to Catharanthus roseus. 
It has been reported that lipid peroxidation, a sensitive response to metal stress, is usually characterized by the contents of Malondialdehyde (MDA) and hydrogen peroxide $\left(\mathrm{H}_{2} \mathrm{O}_{2}\right)$. Some scholars discovered immediate generation of $\mathrm{H}_{2} \mathrm{O}_{2}$ when plants were exposed to high $\mathrm{Cd}$ content, and thus considered $\mathrm{H}_{2} \mathrm{O}_{2}$ as the key molecule that stimulates signal transduction after metal exposure of plants (Mithöfer et al., 2004; Smeets et al., 2008, 2009). Some concluded that the roots of plants, especially the plasma membranes of root cells, are the primary targets of metal action under Cd stress (Cuypers et al., 2009; Vangronsveld and Clijsters, 1994). Because the toxicity of $\mathrm{Cd}^{2+}$ is exerted through membrane damage and inactivation of enzymes. The antioxidation power of cells mainly comes from antioxidants like catalases (CAT), glutathione reductase (GR) (Mittler et al., 2004). The CAT and the GR can detoxify $\mathrm{H}_{2} \mathrm{O}_{2}$ into $\mathrm{H}_{2} \mathrm{O}$ (Gratao et al., 2005; Passardi et al., 2007), and control cellular redox homeostasis within certain limits (Mittler et al., 2004).

Ethylene is an endogenous regulator for plant growth. The hydrocarbon has a strong impact on ripening, abscission and senescence, as well as many other aspects of vegetative growth. The existing studies have shown that ethylene is involved in the plant's response to metal stress (Cao et al., 2007; Iakimova et al., 2005). Under metal stress, the plants will produce much more ethylene than that under normal conditions. This surge in ethylene production occurs when the Cd content exceeds $1 \mathrm{mM}$ (Chen, 2017). Many scholars held that ethylene regulates cellular and developmental processes responding to abiotic stress, highlighting how ethylene is involved in stress responses of plants (Achard et al., 2006; Ahmadi et al., 2018; Ali et al., 2018; Cao et al., 2007; Jung et al., 2009; Wang et al., 2007). Furthermore, ethylene is considered as a stress hormone (Kende, 1993) and ethylene signalling regulates multiple stress responses (Cao et al., 2009). However, it is not clear what specific roles it plays in signalling of stress responses (Cao et al., 2008).

In light of the above, this paper probes deep into the relationship between ethylene and plant resistance to heavy metal stress, aiming to enhance crop yield, improve the crop resistance to heavy metal stress and remediate the soil polluted by heavy metals.

\section{Materials and methods}

\section{Plant and Cd treatment}

Arabidopsis thaliana (Columbia ecotype) (Col-0) seeds were surface sterilized by $10 \%$ (v/v) sodium hypochlorite $(\mathrm{NaClO})$, then washed with water and dried under sterile conditions. The sterilized seeds were then placed on agar plates containing Murashige and Skoog (MS) basal salt mixture, 1\% sucrose, $\mathrm{pH}$ 5.7, 0.8\% Agar. Next, the plates were respectively added $0 \mu \mathrm{M}, 10 \mu \mathrm{M}, 20 \mu \mathrm{M}, 40 \mu \mathrm{M}, 50 \mu \mathrm{M}, 60 \mu \mathrm{M}$ and $100 \mu \mathrm{M}$ $\mathrm{CdCl}_{2}$. The plates were kept in the dark at $4{ }^{\circ} \mathrm{C}$ for a $4 \mathrm{~d}$-long synced germination, before being relocated to light (photosynthetically active radiation $(\mathrm{PAR})=160 \mu \mathrm{M}$ photons $\mathrm{m}^{-2} \mathrm{~s}^{-1}$ ) at $23{ }^{\circ} \mathrm{C}$ with a $16: 8 \mathrm{~h}$ light: dark regime.

\section{Assay of seedling growth}

To measure the growth of Arabidopsis thaliana, the root lengths of at least 15 seedlings were measured daily after the seedlings were transferred to light. The measurements were carried out with an SMZ 1500 stereomicroscope (Nikon, Japan) and the measured data were analysed on NIS-Elements Basic Research (Nikon, Japan). 


\section{Assay of antioxidative enzyme activity}

To evaluate antioxidative enzyme activity, $0.3 \mathrm{~g}$ seedling were ground in liquid nitrogen and extracted in $5 \mathrm{~mL}$ phosphate-buffered saline (PBS) buffer (50 mM, pH7.0), containing $1 \mathrm{mM}$ ethylenediaminetetraacetic acid (EDTA), $1 \mathrm{mM}$ acetylsalicylic acid (ASA) and $1 \%(\mathrm{w} / \mathrm{v})$ soluble polyvinylpyrrolidone (PVP). The homogenates were centrifuged $(10,000 \mathrm{~g})$ for $30 \mathrm{~min}$ at $4{ }^{\circ} \mathrm{C}$, and then the supernatant was collected for the assay of enzyme activities.

The CAT activity was measured by the method of Lin et al. (2013). The $\mathrm{H}_{2} \mathrm{O}_{2}$ (extinction coefficient: $0.04 \mathrm{nM}-1 \mathrm{~cm}-1$ ) was decomposed at $240 \mathrm{~nm}$ for $3 \mathrm{~min}$ in a quartz cuvette. The reaction mix consists of $2.7 \mathrm{~mL} 0.1 \mathrm{M}$ PBS buffer $(\mathrm{pH} 7.0), 0.1 \mathrm{~mL} 300 \mathrm{mM}$ $\mathrm{H}_{2} \mathrm{O}_{2}$ solution and $0.2 \mathrm{~mL}$ extract. All experiments were performed in triplicate for each treatment.

The GR activity was determined by the method of Kaya and Yigit (2012). The glutathione disulphide (GSSG) and reduced nicotinamide adenine dinucleotide phosphate (NADPH) were reduced into glutathione and nicotinamide adenine dinucleotide phosphate $\left(\mathrm{NADP}^{+}\right)$in the presence of GR. The reaction mix consists of $0.5 \mathrm{~mL}$ PBS buffer (pH7.8), 0.1mL 20mM EDTA-Na ${ }_{2}$ solution, $0.1 \mathrm{~mL} 5 \mathrm{mM}$ GSSG solution, $0.1 \mathrm{~mL} 1.5 \mathrm{mM}$ NADPH solution and $0.2 \mathrm{~mL}$ extract. The absorbance of the mixture was measured at $340 \mathrm{~nm}$. The reaction lasted for $3 \mathrm{~min}$. All experiments were performed in triplicate for each treatment.

\section{Determination of $\mathrm{H}_{2} \mathrm{O}_{2}$}

The content $\mathrm{H}_{2} \mathrm{O}_{2}$ was determined by the method of Satterfield and Bonnell (1955) with a little modification. Firstly, about $0.3 \mathrm{~g}$ plant tissue was frozen in liquid nitrogen and then ground into powder. Then, $3 \mathrm{~mL}$ precooled propanone was added and mixed with the powder. After centrifugation, the supernatant was collected for further use. Next, $2 \mathrm{~mL}$ supernatant was taken, and added with $0.1 \mathrm{~mL} 5 \%$ titanium sulphate and $0.2 \mathrm{~mL}$ concentrated ammonia. After centrifugation, the precipitate was collected and washed with propanone, and then added with $5 \mathrm{~mL} 2 \mathrm{M}$ sulfuric acid. The absorbance of the mixture was measured at $415 \mathrm{~nm}$. All experiments were performed in triplicate for each treatment.

\section{Determination of lipid peroxidation}

The lipid peroxidation was determined by the method of Ashraf et al. (2015). The thiobarbituric acid reactive substances (TBARS) were taken as the measure of lipid peroxidation. Firstly, $300 \mathrm{mg}$ plant tissue was homogenized with $3 \mathrm{~mL} 10 \%$ precooled trichloroacetic acid (TCA) buffer. After centrifugation $(8,000 \mathrm{~g})$ for $10 \mathrm{~min}$ at $4{ }^{\circ} \mathrm{C}, 2$ $\mathrm{mL} 0.5 \%$ TBA was added to $2 \mathrm{~mL}$ extract. Then, the mixture was heated for $30 \mathrm{~min}$ at $95^{\circ} \mathrm{C}$ and centrifuged. Finally, the absorbance of the supernatant was measured at 532 $\mathrm{nm}$ and corrected for unspecific absorbance at $600 \mathrm{~nm}$.

\section{Analysis on gene expression}

The total ribonucleic acid (RNA) was extracted from 100 200 mg samples (both leaves and roots), using TRIzol reagent, and quantified by a Nanodrop ND-1000 spectrophotometer (Thermo Fisher Scientific, US) with absorbance at $260 \mathrm{~nm}$. Next, 2 $\mu \mathrm{g}$ RNA was adopted for reverse transcription with a Revert Aid Reverse Transcriptase 
and Oligo (dT) primers (Takara, Japan). The quantitative reverse transcriptionpolymerase chain reaction (qRT-PCR) was analysed on a RealMasterMix Kit (TIANGEN Biotech, China). The initial denaturation lasted $30 \mathrm{~s}$ at $94{ }^{\circ} \mathrm{C}, 30 \mathrm{~s}$ at $60{ }^{\circ} \mathrm{C}$ and $30 \mathrm{~s}$ at $72{ }^{\circ} \mathrm{C}$, followed by a 5 min-long process at $92{ }^{\circ} \mathrm{C}$. All quantifications were normalized to the amplification of Actin2 gene. The primer sequences of all genes used for qRT-PCR are listed in Table 1. All experiments were performed in triplicate for each treatment.

\section{Statistical analysis}

In the present study, there were three replicates arranged in a randomized block design manner for each treatment including control. All the data were presented as mean \pm standard error (SE) and comparison of means were performed using SPSS (SPSS 17.0, SPSS Inc., USA). The one-way ANOVA with the Duncan's post hoc test was performed to test the difference significance $(p<0.05)$ of means.

Table 1. The primer sequences of all genes used for qRT-PCR

\begin{tabular}{c|c|c}
\hline Gene & GeneBankaccession no. & Primers \\
\hline \multirow{2}{*}{ aco2 } & ACO2 $\mathrm{R}$ & TGCAGGAGGCATCATCTTGTT \\
& ACO2 F & AACGATGCAACCGACATCCT \\
\hline \multirow{2}{*}{ acs2 } & ACS2 $\mathrm{R}$ AGGCAATTGCACATTTCATGG \\
& ACS2 F & CTGTCCGCCACCTCAAGTCT \\
\hline \multirow{2}{*}{ ein3 } & EIN3 R & AGGCAGAGACCTTTTTCATCA \\
& EIN3 F & CAGGCTCAGCTTGTGGAACA \\
\hline \multirow{2}{*}{ atm3 } & ATM3 $\mathrm{R}$ & TGCTCGGACATTTTTGAAATC \\
& ATM3 F & GTCCATAGCTGCGCATATCTC \\
\multirow{2}{*}{ pdr8 } & PDR8 $\mathrm{R}$ & CTCTTGATTGGTACAGTCTTCTG \\
& PDR8 F & CCATAATGGTCCTCAATGTATTGC \\
\hline \multirow{2}{*}{ actin2 } & Actin2 $\mathrm{R}$ & TGAGCAAAGAAATCACAGCACT \\
& Actin2 F & CCTGGACCTGCCTCATCATAC \\
\hline
\end{tabular}

\section{Experimental results}

\section{Ethylene synthesis and signal related gene expression}

Figure 1 illustrates the expression of ACO2, ACS2 and EIN3 genes in Arabidopsis thaliana under elevated $\mathrm{Cd}$ content. Obvious changes were seen in the expression of all three genes from the figure. Specifically, ACO2 was expressed more strongly under $\mathrm{Cd}$ stress, except at the Cd content of $10 \mu \mathrm{M}$; ACS2 had a strong expression at the Cd content of $60 \mu \mathrm{M}$; EIN3 expression increased with Cd content. Overall, the strongest synthesis and signal of ethylene gene expressions were observed at the $\mathrm{Cd}$ content of 60 $\mu \mathrm{M}$. This means ethylene is involved to maintain the normal growth of plants under $\mathrm{Cd}$ stress.

\section{Altered element uptake in Arabidopsis thaliana under Cd stress}

Several macro- and micro-nutrients were analysed to disclose the nutrient acquisition in Arabidopsis thaliana seedlings under Cd stress. The seedlings were placed in nutrient solutions with different $\mathrm{Cd}$ contents for $14 \mathrm{~d}$. Then, the $\mathrm{Cd}$ contents in the shoot and the 
root of the seedlings were measured one by one. The results show that, under Cd stress, the $\mathrm{Cd}$ contents in both the shoot and the root are positively correlated with the $\mathrm{Cd}$ content in the solution, while the translocation factor of the shoot is negatively correlated with the $\mathrm{Cd}$ content in the solution.

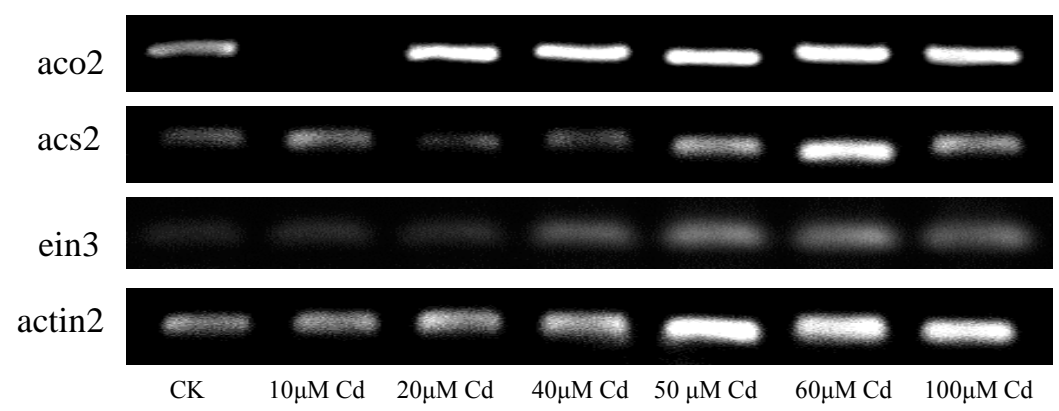

Figure 1. Expression of ACO2, ACS2 and EIN3 in Arabidopsis thaliana under elevated Cd content

\section{Effect of ethylene on Cd content in Arabidopsis thaliana under Cd stress}

The effect of ethylene on Cd content in Arabidopsis thaliana were explored at three $\mathrm{Cd}$ contents. The experimental results are displayed in Figure 2. Compared with the seedlings treated with $\mathrm{Cd}$ alone, the seedings treated with $30 \mu \mathrm{M}$ aminocyclopropane-1carboxylic acid (ACC) had a low $\mathrm{Cd}$ content in the shoots. The same trend was observed in the roots. The translocation factor of seedlings added with ethylene was lower than that of those treated with $\mathrm{Cd}$ alone. To sum up, the ethylene could reduce the $\mathrm{Cd}$ content and translocation factor in Arabidopsis thaliana seedlings under Cd stress.

\section{Effect of ethylene on MDA content in Arabidopsis thaliana under Cd stress}

Plasma membranes are the primary targets for metal stress in both roots and leaves. The membrane damage can be deduced through the TBA assay on lipid peroxidation products. Here, several Arabidopsis thaliana seedlings are treated with different contents of $\mathrm{Cd}$. The results show that the $\mathrm{Cd}$ treatment consistently promoted the MDA contents in leaves of Arabidopsis thaliana seedlings. Hence, three $\mathrm{Cd}$ contents were selected to treat the seedlings, and used to detect the effect of ethylene on MDA contents in leaves. As shown in Figure 3, the seedlings added with ethylene contained fewer MDA than those treated by $\mathrm{Cd}$ alone. Under Cd stress, the application of ethylene suppressed the MDA content, easing the membrane damage caused by lipid peroxidation.

\section{Effect of ethylene on $\mathrm{H}_{2} \mathrm{O}_{2}$ content in Arabidopsis thaliana under Cd stress}

$\mathrm{H}_{2} \mathrm{O}_{2}$ is a common product under metal exposure. Thus, the $\mathrm{H}_{2} \mathrm{O}_{2}$ contents in leaves of Arabidopsis thaliana seedlings were measured at different $\mathrm{Cd}$ contents. The measured results in Figure 4 show that the leaves of seedlings treated with $\mathrm{Cd}$ produced more $\mathrm{H}_{2} \mathrm{O}_{2}$ than the control. Thus, the $\mathrm{Cd}$ content can greatly impact the production of $\mathrm{H}_{2} \mathrm{O}_{2}$ in seedlings. With the increase of $\mathrm{Cd}$ content, the $\mathrm{H}_{2} \mathrm{O}_{2}$ content in leaves of Arabidopsis thaliana gradually increased (Fig. 4). Then, the effect of ethylene on $\mathrm{H}_{2} \mathrm{O}_{2}$ content in the leaves was determined at the $\mathrm{Cd}$ content of $60 \mu \mathrm{M}$. The results indicate that the ethylene inhibited the $\mathrm{H}_{2} \mathrm{O}_{2}$ content in Arabidopsis thaliana seedlings under Cd stress. 

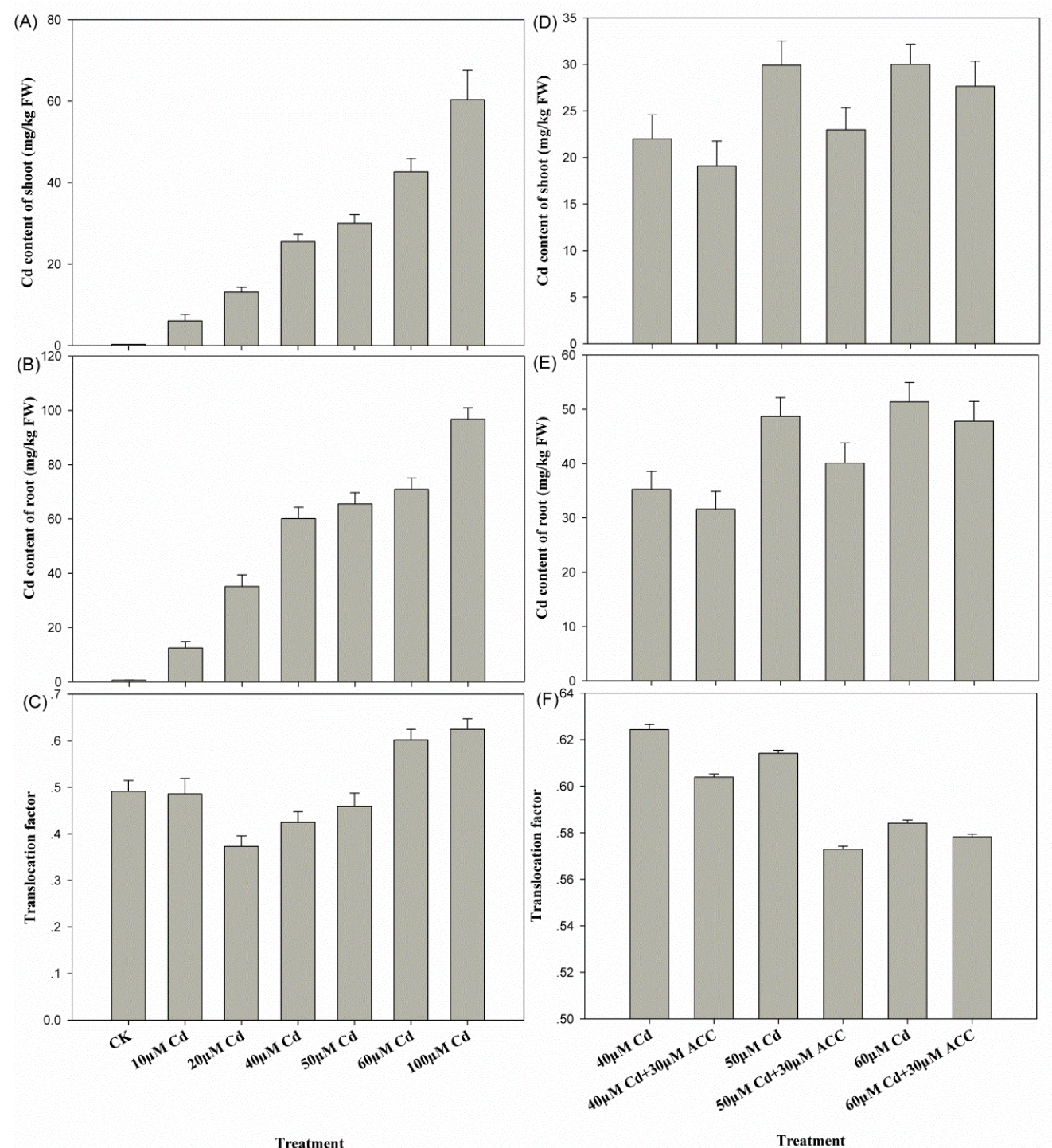

Figure 2. Effect of ethylene on Cd contents of shoots $(A$ and $D)$, roots ( $B$ and $E)$ and $C d$ translocation factors $(C$ and $F$ )
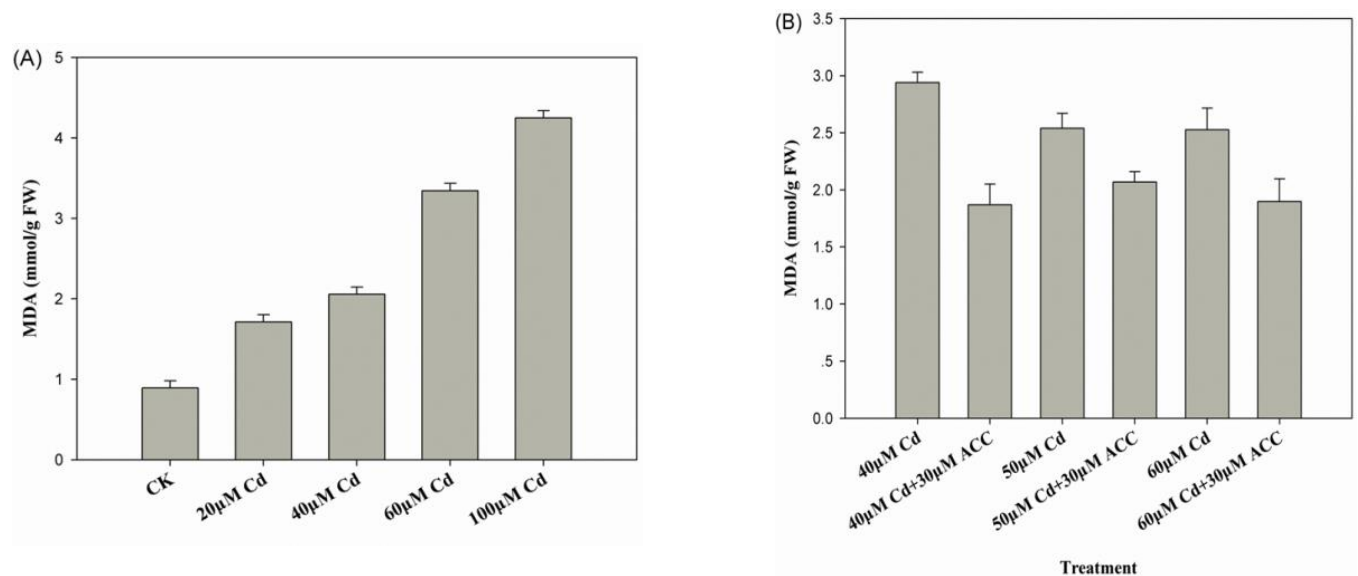

Figure 3. a Effect of Cd on MDA contents in leaves of Arabidopsis thaliana seedlings. $\boldsymbol{b}$ Effect of ethylene on MDA contents in leaves of Arabidopsis thaliana seedlings under Cd stress 

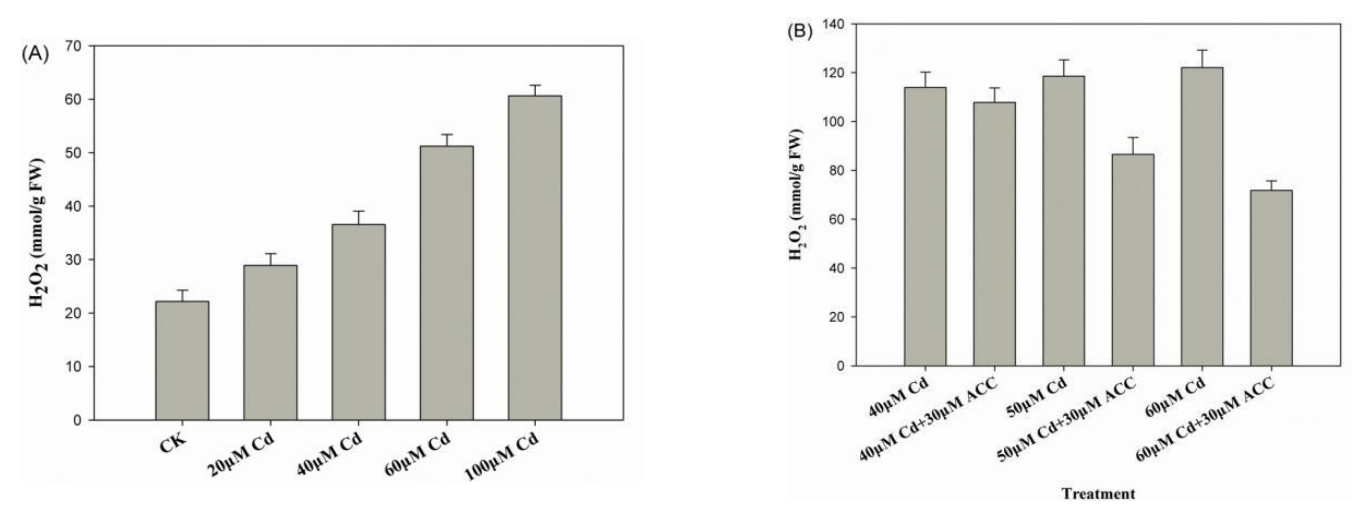

Figure 4. a Effect of $\mathrm{Cd}$ on $\mathrm{H}_{2} \mathrm{O}_{2}$ contents in leaves of Arabidopsis thaliana seedlings. $\boldsymbol{b}$ Effect of ethylene on $\mathrm{H}_{2} \mathrm{O}_{2}$ contents in leaves of Arabidopsis thaliana seedlings under $\mathrm{Cd}$ stress

\section{Antioxidative enzyme activities}

The effects of Cd and ethylene on CAT and GR activities in leaves of Arabidopsis thaliana seedlings were tested, and the results were plotted in Figure 5. Obviously, the $\mathrm{Cd}$ content exhibited a great impact on the antioxidative enzyme activities. The CAT activities in seedlings treated with Cd were greatly affected. Compared with the control, the CAT activities in all seedlings treated with $\mathrm{Cd}$ were relatively low. Next, the $\mathrm{Cd}$ content of $60 \mu \mathrm{M}$ was selected to detect how ethylene affects CAT activity. The detection results show that the ethylene significantly boosted the CAT activities in seedlings under $\mathrm{Cd}$ stress. In addition, the Cd content greatly promoted the GR activities in seedlings, while the growth in ethylene content led to a decline and then increase in the GR activities.
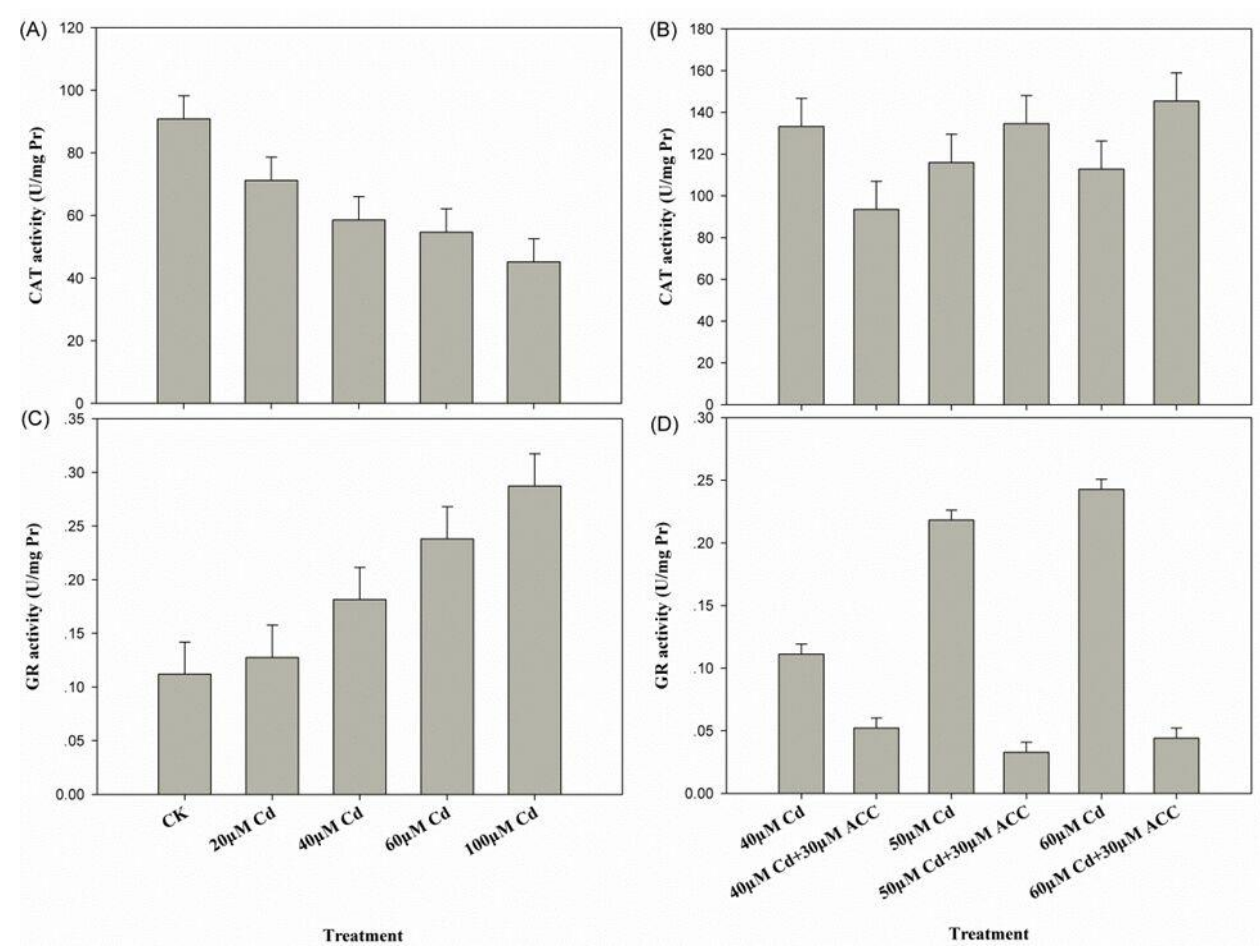

Figure 5. Effect of $C d$ and ethylene on the activities of $C A T(A$ and $B)$ and $G R(C$ and $D)$ in leaves of Arabidopsis thaliana seedlings 


\section{Expression of AtATM3 and AtPDR8 in Arabidopsis thaliana seedlings under Cd stress}

The AtATM3 gene is involved in Cd transporter proteins in the roots of Arabidopsis thaliana seedlings. If this gene is overexpressed, the plant will be more resistant to $\mathrm{Cd}$. Meanwhile, the AtPDR8 gene has been identified as a transporter of ATP-binding cassette (ABC) that contributes to $\mathrm{Cd}$ resistance in Arabidopsis thaliana, as it excludes $\mathrm{Cd}$ or Cd-containing toxic compounds from the cytoplasm. The author tested the expression of AtATM3 and AtPDR8 in Arabidopsis thaliana seedlings treated with different Cd contents. The results (Fig. 6) show that both AtATM3 and AtPDR8 were expressed more stronger with the growth in Cd content, indicating that the two genes contribute to $\mathrm{Cd}$ resistance.

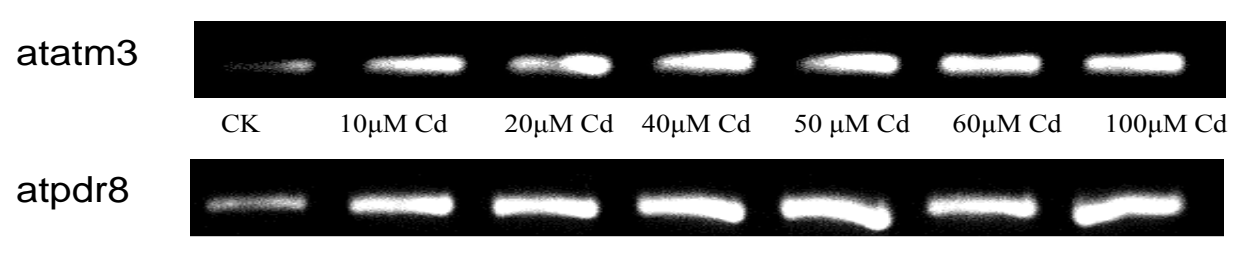

Figure 6. Expression of AtATM3 and AtPDR8 in Arabidopsis thaliana seedlings under different Cd contents

Figure 7 presents how ethylene content affects the expression of AtATM3 and AtPDR8 in Arabidopsis thaliana seedlings under Cd stress. It can be seen that the two genes were expressed more strongly with the $\mathrm{Cd}$ content and with the ethylene content. This means ethylene contributes to $\mathrm{Cd}$ resistance by enhancing the expression of AtATM3 and AtPDR8 (Fig. 7).

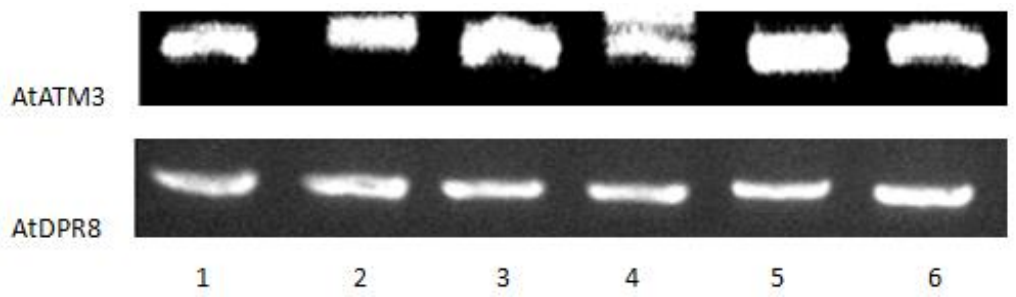

Figure 7. The effect of ethylene content on expression of AtATM3 and AtPDR8 in Arabidopsis thaliana seedlings under $C d$ stress. Note: The treatments are $60 \mu M C d(1), 60 \mu M C d+2 \mu M$ $A C C(2), 60 \mu M C d+\mu M A C C(3), 60 \mu M C d+10 \mu M A C C(4), 60 \mu M C d+30 \mu M A C C(5)$ and $60 \mu M C d+50 \mu M A C C(6)$

\section{Discussion}

This research uses Arabidopsis thaliana seedlings to test the effect of ethylene on $\mathrm{Cd}$ resistance. Ethylene, an important regulator of plant physiology under stress, is deeply involved in the response to abiotic response. In recent years, several reports claim that ethylene could improve Cd resistance (Fuhrer, 1982). In these reports, it is confirmed that ethylene takes part in modulating the cadmium response, but the modulation mechanism is not explained. Therefore, our research attempts to verify the hypothesis that the modulation mechanism works thanks to the ability of ethylene to reduce $\mathrm{Cd}$ 
translocation from roots to shoots in Cd-stressed Arabidopsis thaliana. The research results prove the validity of the hypothesis.

With the increase in metal content in the environment, plants worldwide are suffering from metal phytotoxicity (Chen, 2018). The roots, which are in direct contract with the nutrient solution, often accumulate lots of $\mathrm{Cd}$. Under the stress, there is a cumulative effect on the inhibition and phytotoxicity of roots. Our research results also show that Cd stress could greatly boost the expression of ACO2, ACS2 and EIN3 genes in Arabidopsis thaliana seedlings. Hence, ethylene may play an important role in resistance to $\mathrm{Cd}$.

Over the time, the heavy amount of $\mathrm{Cd}$ accumulated in roots under $\mathrm{Cd}$ stress will gradually move to the shoots. With the growth in Cd content, both shoots and roots will witness an increase in their $\mathrm{Cd}$ contents. In our research, the root-shoot $\mathrm{Cd}$ transport is measured by the translocation factor. Our results show that the translocation factor of shoots first decreased and then increased with the increase in $\mathrm{Cd}$ content. Under a high translocation factor, lots of heavy metals were transported from roots to shoots. Thus, a high translocation factor does not contribute to the $\mathrm{Cd}$ resistance. After adding ethylene to Cd-stressed seedlings, it is observed that the Cd content in the seedlings decreased. Besides, the addition of ethylene significantly suppressed the translocation factor under the $50 \mu \mathrm{M}$ Cd stress.

The cellular redox state is an important determinant of metal phytotoxicity (Kranner et al., 2010). Lipid peroxidation could be the first indication of oxidative damage and was observed under $\mathrm{Cd}$ exposure. There is a mutual promotion relationship between lipid peroxidation and the production of hydroxyl radicals. In our experiment, when seedlings were treated with $\mathrm{Cd}$ alone, the MDAs in roots and leaves increased gradually with the Cd content. Comparatively, the roots had higher MDA than leaves, and thus suffered more injuries under Cd stress. When ethylene of different contents was applied to the Cd-stressed seedlings, the MDA contents dropped across the board. This means ethylene could ease the membrane injury caused by lipid peroxidation in Cd-stressed plants. During lipid catabolism, $\mathrm{H}_{2} \mathrm{O}_{2}$ is generated as a by-product of fatty acid oxidation (Sharma et al., 2012). However, excess $\mathrm{H}_{2} \mathrm{O}_{2}$ may bring oxidative damage to plants. In our experiment, the $\mathrm{H}_{2} \mathrm{O}_{2}$ content in the leaves of Arabidopsis thaliana seedlings gradually increased with the Cd content. The trend is the same with that of the MDA. Thus, the addition of ethylene could suppress the $\mathrm{H}_{2} \mathrm{O}_{2}$ content in Cd-stressed seedlings.

In leaves, the $\mathrm{H}_{2} \mathrm{O}_{2}$-scavenging enzymes are key weapons of the antioxidative defence system (Skulachev, 1997). Major $\mathrm{H}_{2} \mathrm{O}_{2}$-scavenging enzymes of plants include the CAT, the GR, the ascorbate peroxidase (APX), the superoxide dismutase (SOD), and the peroxidase (POD). Among them, the CAT and the GR were selected for our research. The experiment shows that the CAT ability in seedlings treated by $\mathrm{Cd}$ alone was poorer than that of the control, indicating that the Cd-exposure suppressed the activity of the $\mathrm{H}_{2} \mathrm{O}_{2}$-scavenging enzyme, and boosted the production of $\mathrm{H}_{2} \mathrm{O}_{2}$. However, the CAT ability improved after the addition of ethylene, revealing the promotional effect of ethylene on the CAT. With the growth in Cd content, the GR activity exhibited an increasing trend. This is because the GR can produce the GSH to eliminate $\mathrm{H}_{2} \mathrm{O}_{2}$ and combine with $\mathrm{Cd}$ to yield PCs. As a result, heavy metals are combined with proteins, malic acid and other substances in the cells. However, the GR activity was weakened after ethylene was added, meaning ethylene could suppress GR ability. 
AtATM3 is a transporter protein involved in the root-shoot $\mathrm{Cd}$ transport in Arabidopsis thaliana (Kim et al., 2006). Our research shows that the AtATM3 was upregulated in the roots of seedlings with the increase of $\mathrm{Cd}$ content, and overexpression of the gene could enhance $\mathrm{Cd}$ resistance. Besides, it is learned that ethylene can enhance AtATM3 expression to resist the Cd. Specifically, the ethylene retains the $\mathrm{Cd}$ ions in roots, lowering the translocation factor. In some plants, about $90 \%$ of the $\mathrm{Cd}$ ions are combined with $\mathrm{PC}_{\mathrm{S}}$. In our experiment, about $60 \%$ absorbed in the roots existed as PC-Cd compounds. Meanwhile, AtPDR8 is an ABC transporter capable of excluding $\mathrm{Cd}$ or $\mathrm{Cd}$-containing toxic compounds from the cytoplasm (Kim et al., 2010). Our research shows that the overexpression of this gene enhances Cd resistance, and that ethylene improves AtPDR8 gene expression to resist $\mathrm{Cd}$.

\section{Conclusions}

Our research results demonstrate the key role of ethylene in alleviating the metal phytotoxicity of Cd stress. Ethylene is involved in plant responses to $\mathrm{Cd}$ stress, ensuring the normal growth of plants. The application of ethylene is an effective way to enhance the Cd resistance. Taking Arabidopsis thaliana for example, ethylene reduces the rootshoot translocation of $\mathrm{Cd}$ ions, leading to stronger $\mathrm{Cd}$ resistance. In addition, ethylene can ease the metal phytotoxicity of $\mathrm{Cd}$ by lowering the MDA content and $\mathrm{H}_{2} \mathrm{O}_{2}$ generation, and regulate the over-expression of AtATM3 and APDR8 to enhance Cd resistance. To sum up, the ethylene mainly bolsters $\mathrm{Cd}$ resistance of plants by enhancing antioxidant activity and suppressing the root-shoot translocation of $\mathrm{Cd}$ ions. It is worthing that related antioxidative substance should be further studied in the future.

Acknowledgements. This work was supported by Nantong Science and Technology Foundation of China (JC2018159) and the Research Initiation Funds for Nantong University (03081171).

\section{REFERENCES}

[1] Achard, P., Cheng, H., De Grauwe, L., Decat, J., Schoutteten, H., Moritz, T., Van Der Straeten, D., Peng, J., Harberd, N. P. (2006): Integration of plant responses to environmentally activated phytohormonal signals. - Science 311(5757): 91-94.

[2] Ahmadi, M. H., Hajizadeh, F., Rahimzadeh, M., Shafii, M. B., Chamkha, A. J., Lorenzini, G., Ghasempour, R. (2018): Application GMDH artificial neural network for modeling of Al2O3/water and Al2O3/Ethylene glycol thermal conductivity. International Journal of Heat and Technology 36(3): 773-782.

[3] Ali, F., Arif, M., Khan, I., Sheikh, N. A., Saqib, M. (2018): Natural convection in polyethylene glycol-based molybdenum disulfide nanofluid with thermal radiation, chemical reaction and ramped wall temperature. - International Journal of Heat and Technology 36(2): 619-631.

[4] Ashraf, M. A., Rasheed, R., Hussain, I., Iqbal, M., Haider, M. Z., Parveen, S., Sajid, M. A. (2015): Hydrogen peroxide modulates antioxidant system and nutrient relation in maize (Zea mays L.) under water-deficit conditions. - Archives of Agronomy \& Soil Science 61(4): 507-523.

[5] Cao, S., Chen, Z., Liu, G., Jiang, L., Yuan, H., Ren, G., Bian, X., Jian, H. Y., Ma, X. (2009): The Arabidopsis ethylene-insensitive 2 gene is required for lead resistance. Plant Physiology \& Biochemistry 47(4): 308-312. 
[6] Cao, W. H., Liu, J., He, X. J., Mu, R. L., Zhou, H. L., Chen, S. Y. (2007): Modulation of ethylene responses affects plant salt-stress responses. - Plant Physiology 143(2): 707719.

[7] Cao, Y. R., Chen, S. Y., Zhang, J. S. (2008): Ethylene signaling regulates salt stress response: an overview. - Plant Signaling \& Behavior 3(10): 761-763.

[8] Chen, Q., Wu, K., Tang, Z., Guo, Q. X., Guo, X., Wang, H. (2017): Exogenous ethylene enhanced the cadmium resistance and changed the alkaloid biosynthesis in Catharanthus roseus seedlings. - Acta Physiologiae Plantarum 39(12): 267-272.

[9] Chen, Q., Lu, X., Guo, X., Pan, Y., Yu, B., Tang, Z. (2018): Differential responses to cd stress induced by exogenous application of $\mathrm{Cu}, \mathrm{Zn}$ or $\mathrm{Ca}$ in the medicinal plant Catharanthus roseus. - Ecotoxicol Environ Saf 157: 266-275.

[10] Cuypers, A., Smeets, K., Vangronsveld, J. (2009): Heavy Metal Stress in Plants. - In: Hirt, H. (Ed.) Plant stress Biology: From Genomics to Systems Biology; Wiley-VCH: Verlag: Weinheim, Germany, 161-178.

[11] Fuhrer, J. (1982): Ethylene biosynthesis and cadmium toxicity in leaf tissue of beans (Phaseolus vulgaris 1.). - Plant Physiology 70(1): 162-167.

[12] Gratao, P. L., Polle, A., Lea, P. J., Azevedo, R. A. (2005): Making the life of heavy metal-stressed plants a little easier. - Functional Plant Biology 32(6): 481-494.

[13] Gratão, P. L., Monteiro, C. C., Carvalho, R. F., Tezotto, T., Piotto, F. A., Peres, L. E. (2012): Biochemical dissection of diageotropica and never ripe tomato mutants to cdstressful conditions. - Plant Physiol Biochem 56: 79-96.

[14] Iakimova, E., Kapchinatoteva, V., Jong, A. D., Atanassov, A., Woltering, E. (2005): Involvement of ethylene, oxidative stress and lipid-derived signals in cadmium-induced programmed cell death in tomato suspension cells. - BMC Plant Biology 5(S1): S19-S19.

[15] Järup, L., Akesson, A. (2009): Current status of cadmium as an environmental health problem. - Toxicology \& Applied Pharmacology 238(3): 201-208.

[16] Jung, J. Y., Shin, R., Schachtman, D. P. (2009): Ethylene mediates response and tolerance to potassium deprivation in Arabidopsis. - Plant Cell 21(2): 607-621.

[17] Kaya, A., Yigit, E. (2012): Interactions among glutathione s-transferase, glutathione reductase activity and glutathione contents in leaves of Vicia faba, L. subjected to flurochloridone. - Fresenius Environmental Bulletin 21(6): 344-350.

[18] Kende, H. (1993): Ethylene biosynthesis. - Annual Review of Plant Biology 44(44): 283307.

[19] Kim, D. Y., Bovet, L., Kushnir, S., Noh, E. W., Martinoia, E., Lee, Y. (2006): AtATM3 is involved in heavy metal resistance in Arabidopsis. - Plant Physiology 140(3): 922-932.

[20] Kim, D. Y., Bovet, L. M., Martinoia, E., Lee, Y. (2010): The ABC transporter AtPDR8 is a cadmium extrusion pump conferring heavy metal resistance. - Plant Journal 50(2): 207218.

[21] Kranner, I., Roach, T., Beckett, R. P., Whitaker, C., Minibayeva, F. V. (2010): Extracellular production of reactive oxygen species during seed germination and early seedling growth in Pisum sativum. - Journal of Plant Physiology 167(10): 805-811.

[22] Lin, Y., Chen, D., Paul, M., Zu, Y., Tang, Z. (2013): Loss-of-function mutation of ein2 in arabidopsisexaggerates oxidative stress induced by salinity. - Acta Physiologiae Plantarum 35(4): 1319-1328.

[23] Mishra, S., Srivastava, S., Tripathi, R. D., Govindarajan, R., Kuriakose, S. V., Prasad, M. (2006): Phytochelatin synthesis and response of antioxidants during cadmium stress in Bacopa monnieri L\{lozenge, open. - Plant Physiology and Biochemistry 44(1): 25-37.

[24] Mithöfer, A., Schulze, B., Boland, W. (2004): Biotic and heavy metal stress response in plants: evidence for common signals. - Febs Letters 566(1): 1-5.

[25] Mittler, R., Vanderauwera, S., Martin, G., Van Breusegemb, F. (2004): Reactive oxygen gene network of plants. - Trends in Plant Science 9(10): 490-498.

[26] Monteiro, C. C., Carvalho, R. F., Gratão, P. L., Carvalho, G., Tezotto, T., Medici, L. O. (2011): Biochemical responses of the ethylene-insensitive never ripe, tomato mutant 
subjected to cadmium and sodium stresses. - Environmental \& Experimental Botany 71(2): 306-320.

[27] Passardi, F., Theiler, G., Zamocky, M., Cosio, C., Rouhier, N., Teixera, F. (2007): Peroxibase: the peroxidase database. - Phytochemistry 68(12): 1605-1611.

[28] Ranieri, A., Castagna, A., Scebba, F., Careri, M., Zagnoni, I., Predieri, G. (2005): Oxidative stress and phytochelatin characterisation in bread wheat exposed to cadmium excess. - Plant Physiology \& Biochemistry Ppb 43(1): 45-54.

[29] Satterfield, C. N., Bonnell, A. H. (1955): Interferences in titanium sulfate method for hydrogen peroxide. - Analytical Chemistry 27(7): 1174-1175.

[30] Schützendübel, A., Nikolova, P., Rudolf, C., Polle, A. (2002): Cadmium and $\mathrm{H}_{2} \mathrm{O}_{2}$ induced oxidative stress in populus $\times$ canescens, roots. - Plant Physiology \& Biochemistry 40(6): 577-584.

[31] Sharma, P., Jha, A. B., Dubey, R. S., Pessarakli, M. (2012): Reactive oxygen species, oxidative damage, and antioxidative defense mechanism in plants under stressful conditions. - Journal of Botany 2012: 1-26.

[32] Shen, L. (2008): Improvement in cadmium tolerance of tomato seedlings with an antisense dna for 1-aminocyclopropane-1-carboxylate synthase. - Journal of Plant Nutrition 31(5): 809-827.

[33] Skulachev, V. P. (1997): Membrane-linked systems preventing superoxide formation. Bioscience Reports 17(3): 347-366.

[34] Smeets, K., Ruytinx, J., Semane, B., Belleghem, F. V., Remans, T., Sanden, S. V. (2008): Cadmium-induced transcriptional and enzymatic alterations related to oxidative stress. Environmental \& Experimental Botany 63(1): 1-8.

[35] Smeets, K., Opdenakker, K., Remans, T., Van, S. S., Van, B. F., Semane, B. (2009): Oxidative stress-related responses at transcriptional and enzymatic levels after exposure to cd or cu in a multipollution context. - Journal of Plant Physiology 166(18): 1982-1992.

[36] Vangronsveld, J., Clijsters, H. (2008): Toxic Effects of Metals. - In: Farago, M. E. (ed.) Plants and the Chemical Elements: Biochemistry, Uptake, Tolerance and Toxicity. Wiley, New York, pp. 149-177.

[37] Wang, Y., Liu, C., Li, K., Sun, F., Hu, H., Li, X., Zhao, Y., Han, C., Zhang, W., Duan, Y., Liu, M., Li, X. (2007): Arabidopsis ein2 modulates stress response through abscisic acid response pathway. - Plant Molecular Biology 64(6): 633-644.

[38] Wang, Y., Zong, K., Jiang, L., Sun, J., Ren, Y., Sun, Z. (2011): Characterization of an Arabidopsis cadmium-resistant mutant cdr3-1d reveals a link between heavy metal resistance as well as seed development and flowering. - Planta 233(4): 697-706.

[39] Zhang, Z. H., Meney, Z. R. K. (2010): Cadmium accumulation and translocation in four emergent wetland species. - Water Air \& Soil Pollution 212(1-4): 239-249. 